\title{
Light management with sinusoidal nanotextures
}

\author{
Klaus Jäger, ${ }^{1,2, *}$ Phillip Manley, ${ }^{1,2}$ David Eisenhauer, ${ }^{1}$ \\ Philipp Tockhorn, ${ }^{1}$ Johannes Sutter, ${ }^{1}$ Martin Hammerschmidt, ${ }^{2}$ \\ Sven Burger, ${ }^{2}$ Steve Albrecht ${ }^{1}$ and Christiane Becker ${ }^{1}$ \\ ${ }^{1}$ Helmholtz-Zentrum Berlin für Materialien und Energie, Hahn-Meitner Platz 1, 14019 Berlin, Germany \\ ${ }^{2}$ Zuse Institute Berlin, Takustraße 7, 14195 Berlin, Germany \\ *klaus.jaeger@helmholtz-berlin.de
}

\begin{abstract}
Nanoimprint lithography can be used to fabricate sinusoidal nanotextures on a large scale. We present optical and numerical results for sinusoidal nanotextures in two types of solar cells: thin film c-Si and perovskite-silicon tandem solar cells.

OCIS codes: (350.6050) Solar energy; (040.5350) Photovoltaic; (000.4430) Numerical approximation and analysis; (310.1210) Antireflection coatings;
\end{abstract}

\section{Introduction}

Light management is vital for all high-efficiency solar cell concepts in order to reduce the reflective losses and increase the average light path length for enhanced absorption in the absorber layer. The latter is especially important for weakly absorbing materials such as silicon in the infrared.

In conventional wafer-based silicon solar cells, pyramids with characteristic dimensions in the micrometer range are used for light management. For thin-film concepts smaller features are required, which happen usually to be comparable to the relevant wavelength of light. This necessitates a wave optical approach, such as sinusoidal hexagonal nanotextures illustrated in Fig. 1(a). Due to their smooth nature they can be applied for solar cells types where sharp features would negatively affect the electrical solar cell performance [1].

In this contribution we present two types of solar cells, for which we successfully applied hexagonal sinusoidal nanotextures: (1) thin-film c-Si solar cells, where the absorber is fabricated using a liquid-phase crystallisation (LPC) process and (2) perovskite-silicon tandem solar cells, where sinusoidal nanotextures are used to texture the perovskite top cell. For both applications, we present numerical and experimental results.

\section{Thin-film c-Si solar cells}

Liquid-phase crystallisation (LPC) allows for the fabrication of high-quality c-Si layers on glass with thicknesses up to $40 \mu \mathrm{m}$ [2]. With this technology, a power conversion efficiency (PCE) of 14.2\% has been demonstrated [3]. The record cell shows a short-circuit current density of $J_{\mathrm{sc}}=29.0 \mathrm{~mA} / \mathrm{cm}^{2}$, which is low compared to record silicon solar cells. Hence, light management for a higher $J_{\mathrm{sc}}$ is vital to improve the PCE.

Nanoimprint lithography can be used for manufacturing LPC-Si solar cells with sinusoidal nanotextures between the glass superstrate and the LPC-Si layer. These nanotextures not only decrease reflective losses just as effectively as nanopillars, but do not deteriorate the electrical properties, allowing open circuit voltages exceeding $600 \mathrm{mV}$ [4].

We performed optical simulations with the finite element method (FEM) on the structure illustrated in Fig. 1(b) [5]. In order to reach good agreement with measured reflectivity spectra, the reflection at the glass-air interface had to be corrected with a scattering matrix approach [6], as shown in Fig. 1(c).

\section{Perovskite-silicon tandem solar cells}

Multi-junction solar cells are the most promising route to surpass the 29.4\% PCE limit for c-Si solar cells [7] —and indeed recently a monolithic perovskite-silicon solar cell with 27.3\% PCE was presented [8], which is higher than the c-Si record of $26.7 \%$ [9].

We performed numerical simulations for perovskite-Si solar cells with a $160 \mu \mathrm{m}$ thick c-Si absorber, illustrated in Fig. 1(d). We assumed perfect Lambertian light trapping at the rear side of the bottom cell [10]. As shown in Fig. 1(e). with the best sinusoidal texture (500 $\mathrm{nm}$ period and peak-to-valley height), the reflective losses could be reduced from $5.5 \mathrm{~mA} / \mathrm{cm}^{2}$ to $2.8 \mathrm{~mA} / \mathrm{cm}^{2}$ with respect to a device with a planar perovskite top cell.

Figure 1(f) shows an SEM image of a spin-coated perovskite layer on a sinusoidally textured substrate. This proves that our sinusoidal nanotextures are compatible with spin-coating processes [10]. 
(a)

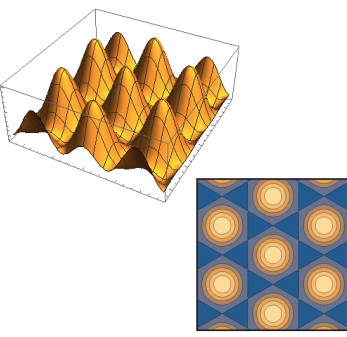

(b)

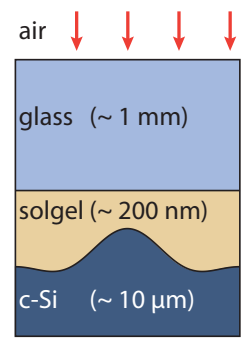

(c)

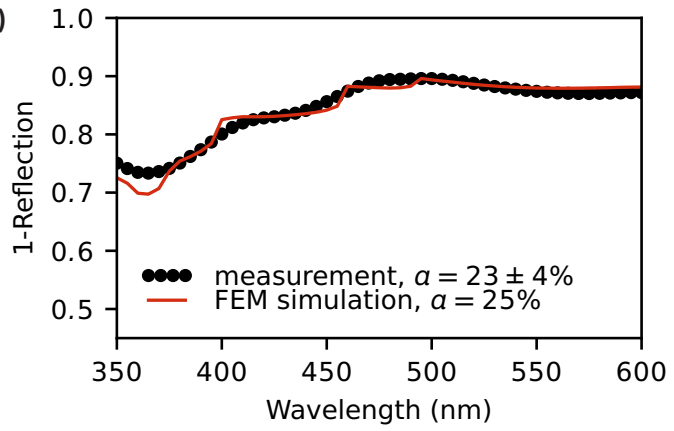

(d)

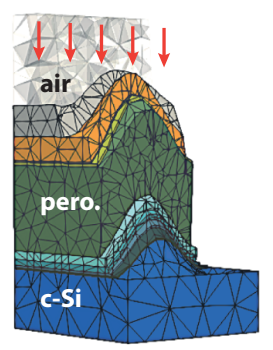

(e)

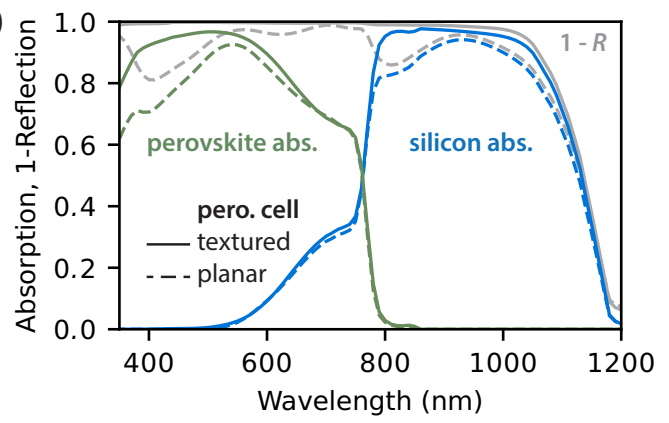

(f)

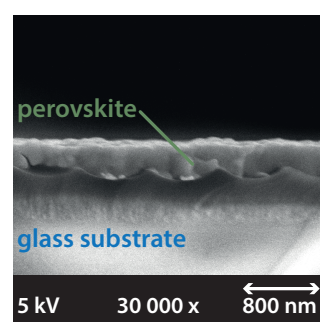

Fig. 1. (a) Illustrating sinusoidal hexagonal textures. (b) A nanotexture between glass and c-Si, as in LPC-Si solar cells. (c) Simulation results and measurements of $1-R$ for $500 \mathrm{~nm}$ period; $a$ denotes the aspect ratio [6]. (d) FEM grid for a nanotextured perovskite-Si cell [10]. (e) Simulated absorption spectra and $1-R$ for cells with a planar perovskite front side or a textured perovskite front side [10]. We assumed Lambertian scattering at the rear side of Si. (f) An SEM picture of a spin-coated perovskite layer on a sinusoidally nanotextured substrate.

\section{Conclusions and outlook}

Sinusoidal nanotextures are well suited for light management in LPC-Si and perovskite-Si tandem solar cells. Because of their smooth nature they maintain electrical performance while providing excellent light trapping. In a next step we plan to build fully-textured perovskite-silicon solar cells.

\section{References}

1. V. Preidel, D. Amkreutz, J. Haschke, M. Wollgarten, B. Rech, and C. Becker, "Balance of optical, structural, and electrical properties of textured liquid phase crystallized Si solar cells," J. Appl. Phys. 117, 225,306 (2015).

2. J. Haschke, D. Amkreutz, and B. Rech, "Liquid phase crystallized silicon on glass: Technology, material quality and back contacted heterojunction solar cells," Jpn. J. Appl. Phys. 55, 04EA04 (2016).

3. C. T. Trinh, N. Preissler, P. Sonntag, M. Muske, K. Jäger, M. Trahms, R. Schlatmann, B. Rech, and D. Amkreutz, "Potential of interdigitated back-contact silicon heterojunction solar cells for liquid phase crystallized silicon on glass with efficiency above 14\%," Sol. Energ. Mat. Sol. C. 174, 187 - 195 (2018).

4. G. Köppel, B. Rech, and C. Becker, "Sinusoidal nanotextures for light management in silicon thin-film solar cells," Nanoscale 8, 8722-8728 (2016).

5. K. Jäger, C. Barth, M. Hammerschmidt, S. Herrmann, S. Burger, F. Schmidt, and C. Becker, "Simulations of sinusoidal nanotextures for coupling light into c-Si thin-film solar cells," Opt. Express 24, A569-A580 (2016).

6. K. Jäger, G. Köppel, M. Hammerschmidt, S. Burger, and C. Becker, "On accurate simulations of thin-film solar cells with a thick glass superstrate," Opt. Express 26, A99-A107 (2018).

7. A. Richter, M. Hermle, and S. Glunz, "Reassessment of the limiting efficiency for crystalline silicon solar cells," IEEE J. Photovolt. 3, 1184-1191 (2013).

8. Oxford PV (2018). https://www.oxfordpv.com/news/oxford-pv-sets-world-record-perovskite-solar-cell.

9. M. A. Green, Y. Hishikawa, E. D. Dunlop, D. H. Levi, J. Hohl-Ebinger, and A. W. Ho-Baillie, "Solar cell efficiency tables (version 51)," Progress in Photovoltaics: Research and Applications 26, 3-12 (2018).

10. D. Chen, P. Manley, P. Tockhorn, D. Eisenhauer, G. Köppel, M. Hammerschmidt, S. Burger, S. Albrecht, C. Becker, and K. Jäger, "Nanophotonic light management for perovskite-silicon tandem solar cells,” J. Photonics Energy 8, 022,601 (2018). 